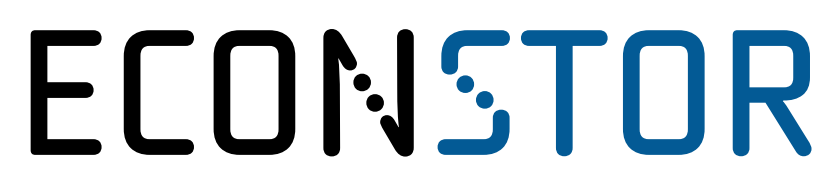

UWU.ECONSTOR.EU

Der Open-Access-Publikationsserver der ZBW - Leibniz-Informationszentrum Wirtschaft The Open Access Publication Server of the ZBW-Leibniz Information Centre for Economics

Josheski, Dushko

\title{
Preprint
}

\section{Essential themes in Personnel economics}

Suggested Citation: Josheski, Dushko (2014) : Essential themes in Personnel economics

This Version is available at:

http://hdl.handle.net/10419/91614

Nutzungsbedingungen:

Die ZBW räumt Ihnen als Nutzerin/Nutzer das unentgeltliche,

räumlich unbeschränkte und zeitlich auf die Dauer des Schutzrechts beschränkte einfache Recht ein, das ausgewählte Werk im Rahmen der unter

$\rightarrow$ http://www.econstor.eu/dspace/Nutzungsbedingungen nachzulesenden vollständigen Nutzungsbedingungen zu vervielfältigen, mit denen die Nutzerin/der Nutzer sich durch die erste Nutzung einverstanden erklärt.
Terms of use:

The ZBW grants you, the user, the non-exclusive right to use the selected work free of charge, territorially unrestricted and within the time limit of the term of the property rights according to the terms specified at

$\rightarrow$ http://www.econstor.eu/dspace/Nutzungsbedingungen $B y$ the first use of the selected work the user agrees and declares to comply with these terms of use. 


\title{
Essential themes in Personnel economics
}

\author{
Dushko Josheski ${ }^{1}$ \\ Researcher in the field of Applied economics mainly, also covers topics from wide area of Macroeconomics, \\ International trade and Econometrics, \\ University Goce Delcev-Stip, R.Macedonia
}

\begin{abstract}
In this paper are presented essential themes in the subject of personnel economics. In the first part analysis has been conducted on the impact of peer pressure on workplace behaviour. Then again models for compensation structures within firms, and their influence on the utility of work by employees. In the final section of the paper the productivity spillover effect has been analyzed, and the causes of existence of spillovers and their impact on workers' productivity.
\end{abstract}

Keywords: Personnel economics, compensation structures, peer pressure, spillover effect

JEL codes: M00, M52,M55

\section{Analysis of the impact of peer pressures on workplace behaviour}

Compensation scheme can be represented: Compensation $=\max (\mathrm{W}, \mathrm{be}-\mathrm{K}) \mathrm{W}$ is guaranteed wage $\mathrm{b}$ is a piece rate based on the number of units of output e and $\mathrm{K}$ is a constant term to satisfy the individual rationality. Situation is presented in Fig. $4^{2}$ Low ability workers have steep indifference curves additional effort must be compensated by a large increase in income, flatter indifference curves are those for higher ability workers hourly wage function starts at zero becomes vertical at $\mathrm{e}_{0}$ and then horizontal at point $\mathrm{A}$. If the workers are offered an hourly wage schedule everyone chooses point A since there is lower utility working at higher levels of effort. High ability workers chose to move from A to B (the tangent point of the budget line and the indifference curve) when piece rate schedule is introduced. Switch in compensation scheme leads to increase in average ability and productivity of workforce and has sorting effect of recruitment of high quality workers, and variance of worker ability to output increases. In table 2 dependent variable is $\log$ of (Output per worker per day) there are 29837 observations. Overall productivity increased about 44\% (an increase in the log of 0.368) as a result from switch from the hourly wage contract to a piece rate and the equation for interpretation is $100 *(\exp b-1) \exp$ of

\footnotetext{
${ }^{1}$ Authors email: dushkojosheski@gmail.com

${ }^{2}$ See Appendix 1
} 
0.368 is 1,44 and that -1 is $0.44 * 100=44 \%$.Second parameter is an increase of output for a given worker after the switch to a piece rates occurred. This is a log increase of 0.197 or interpretation as previous coefficient with antilog as $22 \%$ increase in productivity for average worker. The coefficient before the dummy for workers hired after the piece rate has been implemented is significant; with size $0.243 \mathrm{log}$ showing how higher their productivity is compared with the workers working in hourly wage scheme. The results from Table 5 show that workers who are or have potential to be in a piece rate range experienced an average increase in output of 0.55 units. Those who never reached piece rate range experienced an increase in output of 0.32 units. The output of these workers increased conditional on the high ability workers decision, otherwise we define as peer pressure effect.

\section{Analysis of Lazear and Shaw (2007) model for compensation structures within firms}

In fig. $1^{3}$ is compared Paying for input versus paying for output. Without measuring the individual output (q) firm pays wage ${ }_{1}$ which is the mean of output across the all workers, after incurring fixed measurement costs, the firm pays all the individuals the distribution of wages labelled wage, if the firm does not bear this measurement costs, the best workers in area A will leave the firm for other firms that do measure their output. Also important are the questions how should firms avoid losing "star" workers what is their structure pay for optimal retention of workers. Assume that the workers have output $q$ that varies across the workers in a typical bell shaped curve distribution. Each individual's output is unknown to the firm, because output is costly to measure, output however can be measured at some cost. The firm can forego the measurement, in which case no measurement cost is incurred and no information about workers ability is revealed. So, firm pays a straight salary, which must equal the average output. The firm also can measure the output of its employees and pay workers according to their individual output, which can be called "pay for performance". The distribution of pay matches the distribution of output minus the measurement costs. First implication of the model is that firm will pay for performance when it is cheaper to measure performance, good workers will want their output to be measured. In figure 1workers that are in part A will leave the firm if the firm pays an average wage rather than using pay for performance. The cost of measuring output is decreasing over time due to decreasing technologies. Second implication of this model is when a worker has an alternative high paying jobs, it is important for the firm to pay the worker for what they produce or the firm will lose worker. Third implication is as the lower the tail of distribution of worker quality gets larger, performance pay is more likely to be optimal. Also paying for

\footnotetext{
${ }^{3}$ See Appendix 1
} 
performance induces people to work harder. Workers with high disutility of effort relative to their output will avoid firms that pay for performance. Performance pay is used to induce selection by workers into the right jobs. Also pay for individuals should have less variance than the output. Pay compression is a part of optimal contracts; finally pay compression can be used to insure workers against uncertain outcomes.

\section{What "positive productivity spillover "? Assess the evidence concerning the existence and size of such spillovers provided by Mas and Moretti .}

The introduction of a high productivity worker can increase productivity of incumbent workers as a result of peer effects and it could worsen sometimes because of the free riding effect. This is positive productivity spillover. The spillover is large for workers with above average productivity and small for workers below average productivity Individual specific spillover is a monotonic decreasing function of a worker skill level. The aim is to investigate how workers in a team will react exogenous change in the productivity what is workers utility working in teams $\operatorname{maxU}\left[w_{[}\left(e_{i}\right)\right]-C_{i}\left(e_{i}\right)-P\left(e_{1}, e_{1}, e_{2}, \ldots \ldots \ldots, e_{i-1}, e_{i+1, \ldots m m} e_{W}\right)$ where the last part of the equation is a peer pressure. In the baseline model workers productivity at a given moment of time varies as a function of average permanent productivity we marked permanent co-worker productivity as $\theta_{i}$ this permanent co-worker's productivities are estimated holding constant co-workers composition and therefore do not reflect spillovers. Second regressed are the 10 minute changes in individual productivity on changes in $\bar{\theta}_{-\mathrm{itsz}} \Delta \mathrm{y}_{\mathrm{itcs}}=\rho \Delta \bar{\theta}_{-\mathrm{itsz}}+\psi \Delta \mathrm{X}_{\mathrm{itcs}}+\gamma_{\mathrm{td} \varepsilon}+\mathrm{e}_{\mathrm{itzs}} \mathrm{X}_{\mathrm{itds}}$ is the number of active workers in each 10 minute interval at the relevant store, and $\gamma_{t u s}$ is a set of dummies for each day of the week $* 10$ minute period *store combination .The dependent variable is change in $\log$ productivity of worker $i$. The term $\Delta \bar{\theta}_{-i \text { ites }}$ is the change in average permanent productivity of i's worker from t- 1 to t. In table $6^{4}$ the first column shows that $10 \%$ increase in co-workers productivity is associated with $1.8 \%$ increase in reference worker productivity. This finding indicates that positive spillovers appear to dominate any free riding effect. Entry of a worker with above average permanent productivity is associated with a 1.1\% increase in productivity of co-worker. The exit of an above average co-worker leads to a $0.5 \%$ decline in a productivity relative to the exit of below average co-worker. When a high productivity worker starts a shift, the productivity of other workers rises of about $0.6 \%$, when a

\footnotetext{
${ }^{4}$ See Appendix 2
} 
high productivity worker ends shift the productivity of other workers falls by $0.6 \%$. Column 6 in table 2 shows that most of the spillover effects benefits the productivity of low productivity workers, but high productivity workers are not reducing their productivity in presence of low productivity workers. This finding is important because of its implications for optimal mixing of workers

\section{Three possible causes of such spillovers in the organisations, according of Mas and} Moretti, and the main implications of their paper for hiring wage setting and workforce organisation.

Three possible causes of existence of spillovers are: Social pressure (worker experiences disutility when working lees hard than other workers on shift, but only if co-workers notice), contagious enthusiasm (worker experiences disutility if it is not working hard relative to other workers on a shift, even if no one know that she is working slowly), knowledge spillovers (occur as information is transmitted from one worker to next) ${ }^{5}$. Column 1 of table $6^{6}$ show that just about the entire peer effect is operating through changes in workers that are able to monitor as more productive workers are introduced into a shift, only the co-workers that are in their direct line of vision seem to be more productive, the column 2 model does include dummy for worker in front and worker behind this results from the first two models are consistent with the social pressure. Consistent with social pressure is the addition of worker behind an incumbent worker regardless of her productivity results in an increased productivity of an incumbent worker of $4 \%$ economically and statistically significant, the addition of a worker in front on the other front decreases productivity of the incumbent worker by approximately $3 \%$, the finding suggests that there still is a scope for free-riding. In next column 3 and 4 does physical distance maters is being tested. The social pressure applied by co-worker who are located behind and are closer appear to have a larger effect than the measure applied by coworkers who are behind and are farther. The corresponding coefficient for co-workers who are one or two registers behind the reference worker is 0.16 .The corresponding coefficient for coworkers that are three or four registers behind the reference worker is 0.1.The change in presence of a co-worker one or two positions behind increases $i$ productivity by $2.5 \%$.A change in the presence of co-worker three or four positions behind increases productivity by only

\footnotetext{
${ }^{5}$ See Appendix 2(last table)

${ }^{6}$ See Appendix 2
} 
0.7\%.Table $7^{7}$ on the other hand there are shown estimates of the equation $\Delta y_{i t e s}=\beta_{L} \Delta \bar{\theta}^{\Sigma}-i s t e+\beta_{M} \Delta \bar{\theta}_{-i s t e}^{M}+\beta_{H} \Delta \bar{\theta}_{-i s t e}^{H}+\psi \Delta X_{t e s}+\gamma_{t d s}+e_{i t d s}$ The point estimate $\beta_{L}$ is virtually zero, meaning that the changes in the permanent productivity of co-workers who have had little previous overlap with $i$,have no effect on the change of $i^{\prime} s$ productivity form t-1 to t. $L$ Denotes low schedule overlap M, denotes medium schedule overlap. And overlap means interactions. And changes in the permanent productivity of co-workers with medium and high previous overlap have positive and statistically significant relationship with changes in i's contemporaneous productivity. The entire spillover effect comes from changes in the composition of workers for whom $\mathrm{i}$ is the light of sight. The important finding in table 6 was that there is a relationship between changes in the permanent productivity of i's workers and contemporaneous productivity depending on the spatial orientation of the co-workers in relation with i. In column 3 table 7, we test whether changes in the presence of co-workers, irrespective of their permanent productivity affects i's productivity depending on whether these co-workers have high, medium or low previous overlap with $i$, as well as the spatial orientation of these coworkers in relation to $i$. It has been found that changes in the presence of a co-worker in front of $i$ has either no effect, or negative effect on i's productivity. Workers with low schedule overlap with $i$, their entry is not associated with a statistically significant change in i's productivity. As conclusions from these findings it is important that mix of high and low productivity workers is optimal.

\section{Summary}

Switch in compensation scheme (from guaranteed fixed wage to piece rate) leads to increase in average ability and productivity of workforce and has sorting effect of recruitment of high quality workers, and variance of worker ability to output increases. Workers with high disutility of effort relative to their output will avoid firms that pay for performance. Performance pay is used to induce selection by workers into the right jobs. Also pay for individuals should have less variance than the output. Pay compression is a part of optimal contracts; finally pay compression can be used to insure workers against uncertain outcomes. The introduction of a high productivity worker can increase productivity of incumbent workers as a result of peer effects and it could worsen sometimes because of the free riding effect. Most of the spillover effects benefits the productivity of low productivity workers, but high productivity workers are not reducing their

\footnotetext{
${ }^{7}$ See Appendix 2
} 
productivity in presence of low productivity workers. Three possible causes of existence of spillovers are: Social pressure, contagious enthusiasm, knowledge spillovers.

\section{Appendix 1}

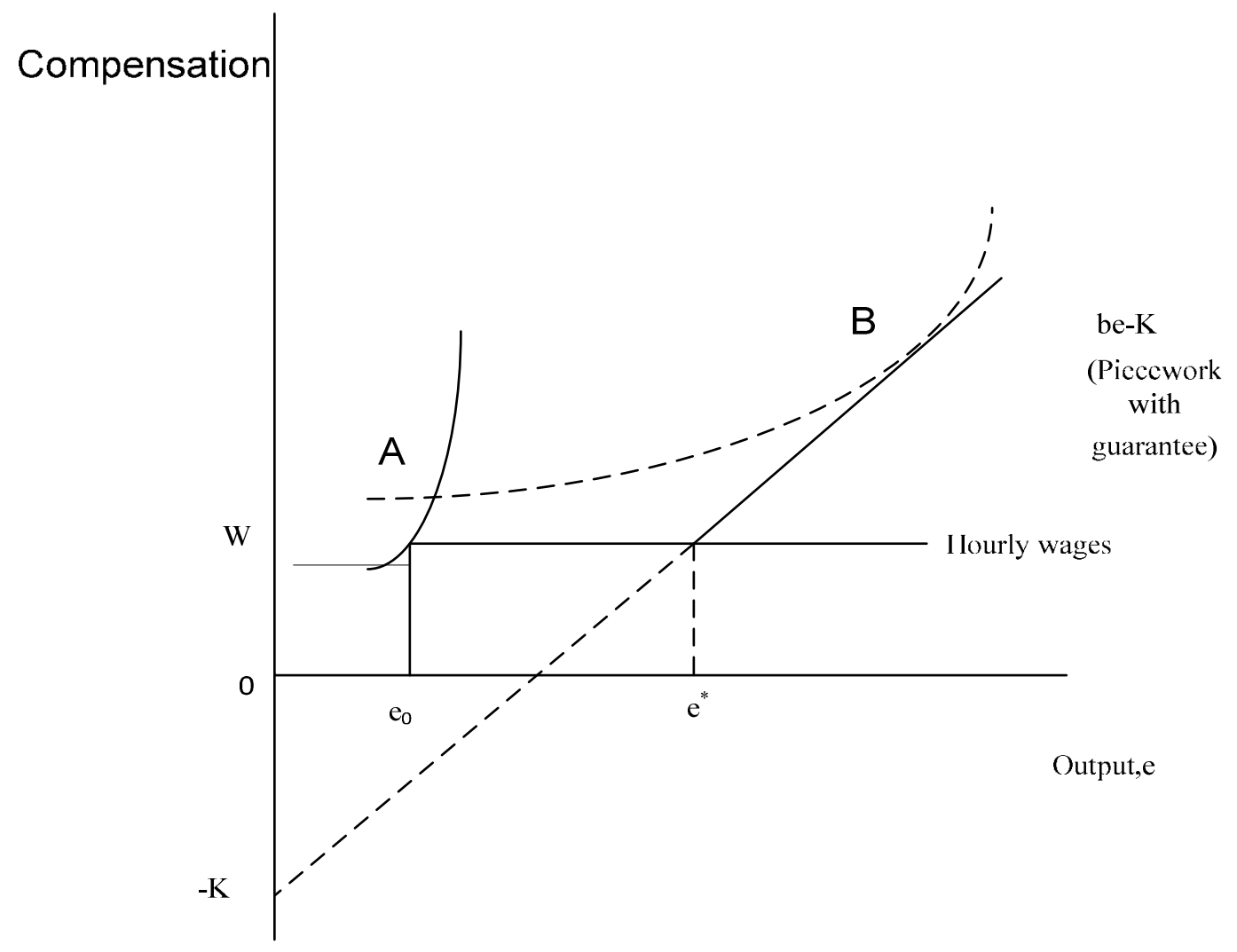


Paying for input versus paying for output

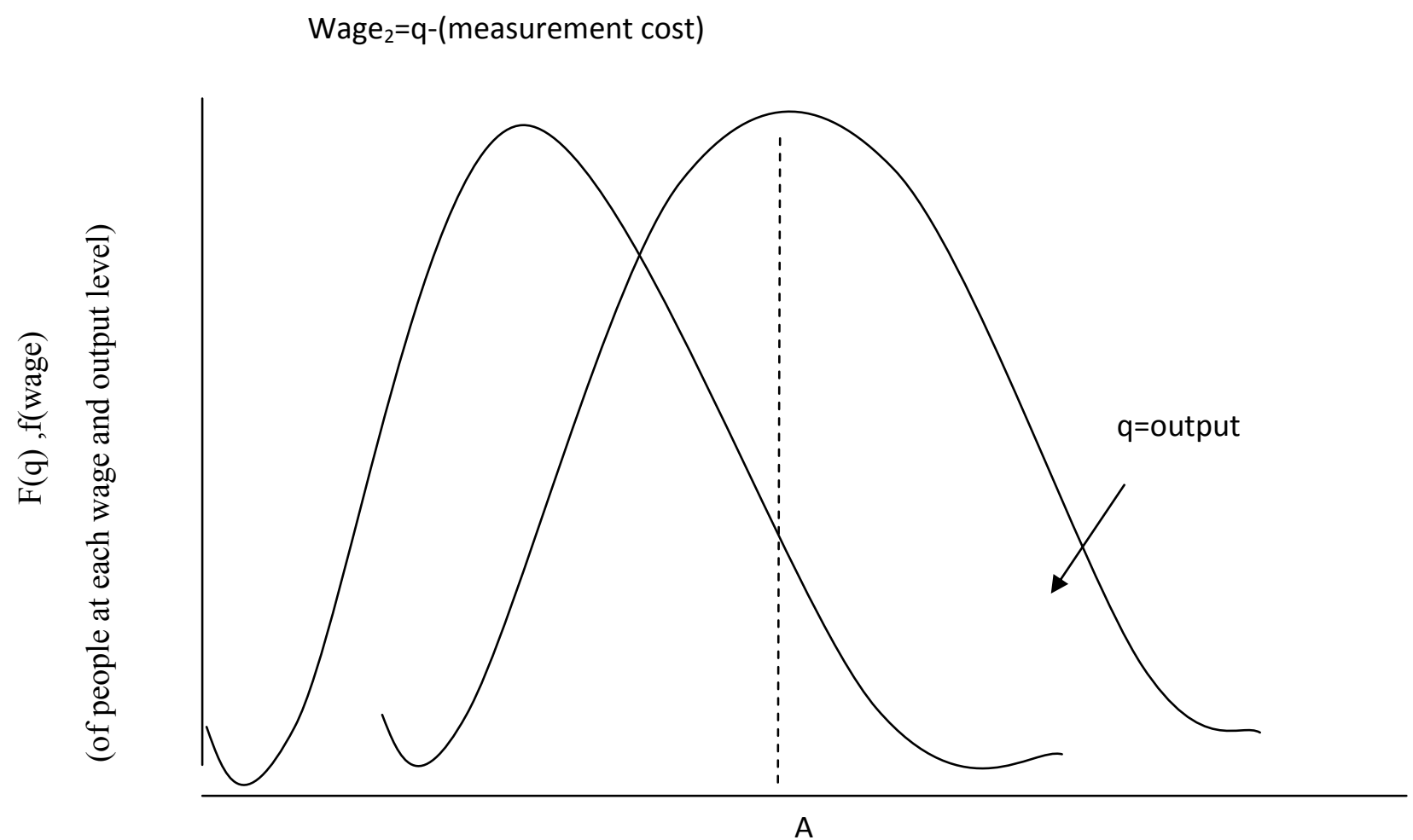

Output, wage

wage $_{1}=$ mean (q) 


\section{Appendix 2}

Table (2) The effect of changes of average co-worker permanent productivity on reference person current productivity

$$
\text { (1) }
$$

(3)

(4)

(5)

(6)

$\Delta$ Co-worker permanent

0.176

0.159

0.160

Productivity

$(0.023)$

$(0.026)$

$\Delta$ Co-worker permanent

$-0.010$

Productivity $\mathrm{y}_{\mathrm{t}+1}$

$(0.026)$

$\Delta$ Co-worker permanent prod.

*Above average worker

Entry of above average

0.011

Productivity worker

(0.001)

Exit of an above average

$-0.005$

Productivity worker

(0.001)

Shift entry of above average

0.006

Productivity worker

$(0.002)$

Shift exit of an above average

$-0.006$

Productivity worker

Observations

$1,734.140$

$1,734.140 \quad 1,734.164 \quad 1,734.164$

$1,356.643$

$1,734.140$

Controls

No

Yes

Yes

Yes

Yes

Yes 
Table 6 The effect of changes of average co-worker permanent productivity on reference person current productivity; Models by spatial orientation and proximity
(1)
(2)
(3)
(4)
(5)

$\Delta$ Co-worker permanent

Productivity behind

$\Delta$ Co-worker permanent

Productivity in front

$\Delta$ Co-worker permanent

productivity behind and closer

$\Delta$ Co-worker permanent

Productivity in front and closer

$\Delta$ Co-worker permanent

Productivity behind and farther

$\Delta$ Co-worker permanent productivity

In front and farther

$\Delta$ Worker behind

$\Delta$ Worker in front

$\Delta$ Worker behind and closer

$\Delta$ Worker in front and closer

$\Delta$ Worker behind and farther

$\Delta$ Worker in front and farther

$\Delta$ Worker behind*

Average FE

$\Delta$ Worker in front*

Average FE

Observations
0.007

(0.018)

0.162

$(0.016)$

0.016

$(0.015)$

0.100

(0.018)

0.003

(0.018)

0.040

0.040

(0.003)

(0.003)

$-0.033$

$-0.033$

(0.003)

(0.003)

0.025

(0.002)

$-0.042$

(0.002)

0.007

(0.002)

0.0001

(0.002)

0.159

$-0.045$

(0.037)

$1,660,312 \quad 1,734,164 \quad 1,501,555 \quad 1,734,164 \quad 1,734,164$ 
Table 7 Mas\&Moretti Peers at work (2006)

Table 7:The Effect of changes of average co-worker permanent productivity on reference person current productivity; Models by previous exposure to co-workers and spatial orientation

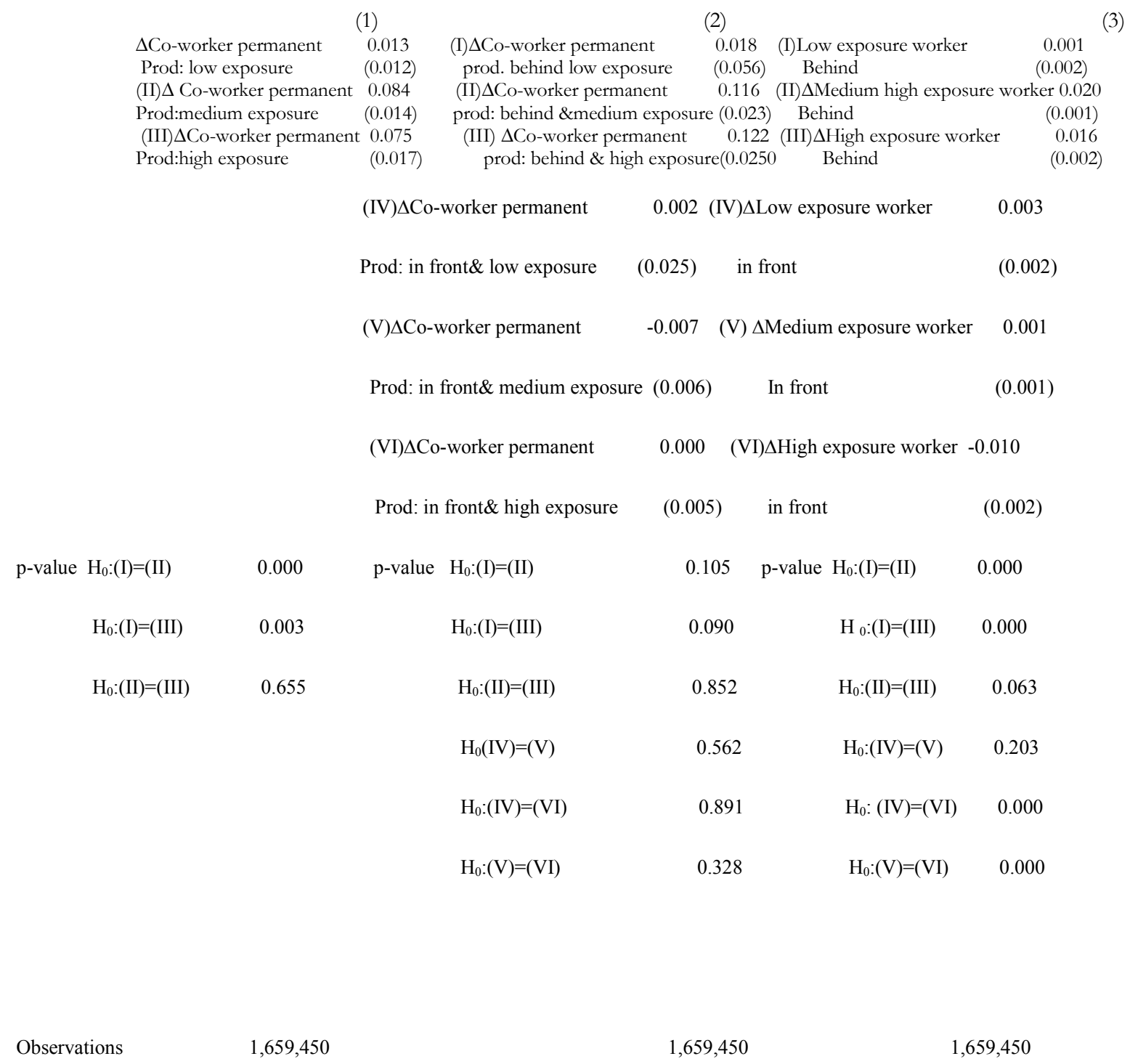


Table Contagious enthusiasm, Social pressure, Knowledge spillover

\begin{tabular}{|l|cc|}
\hline Hypothesis supported & \multicolumn{2}{|c|}{$\begin{array}{c}\text { Spillovers occur when co-worker is } \\
\text { In front Behind Both }\end{array}$} \\
\hline $\begin{array}{l}\text { Contagious enthusiasm } \\
\begin{array}{l}\text { Social pressure } \\
\text { Knowledge spillover }\end{array}\end{array}$ & $\mathbf{X}$ & X \\
\hline
\end{tabular}

\section{References}

1. Lazear,E., 2008. "Personnel economics," The New Palgrave Dictionary of Economics, 2nd Edition, v. 6, p. 380 [pp. 380-84]

2. Lazear,E.,P.,(2000), Performance Pay and Productivity, The American Economic Review, Vol. 90, No. 5 (Dec., 2000), pp. 1346-1361

3. Lazear,E.,P., Shaw,K.L.,( 2007), Personnel Economics: The Economist's View of Human Resources, Journal of Economic Perspectives, American Economic Association, vol. 21(4), pages 91-114, Fall.

4. Mas,A., and Moretti,E.,(2009), Peers at Work, American Economic Review, American Economic Association, vol. 99(1), pages 112-45, March. 